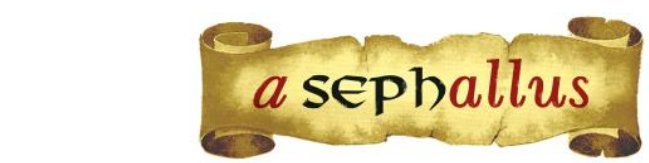

Revista aSEPHallus de Orientação Lacaniana

Núcleo Sephora de Pesquisa sobre o Moderno e o Contemporâneo

ISSN $1809-709 \mathrm{X}$

\title{
Os amores de Frida Kahlo
}

\author{
Aléssia Silva Fontenelle \\ Professora da Universidade Federal do Vale do São Francisco (UNIVASF). Doutoranda do Programa de Pós- \\ Graduação em Teoria Psicanalítica pela Universidade Federal do Rio de Janeiro (UFRJ). Mestrado em \\ Psicologia pela Universidade Federal do Espírito Santo (UFES). Membro da Escola Brasileira de Psicanálise \\ (EBP-Bahia) e da Associação Mundial de Psicanálise (AMP). \\ E-mail: alessia.fontenelle@univasf.edu.br
}

\begin{abstract}
Resumo: O presente artigo pretende abordar o lugar do feminino na clínica contemporânea e os seus embaraços na realização da vida amorosa. Nesse contexto, a questão do amor e dos novos envoltórios sintomáticos demandam respostas singulares, trazendo implicações para a práxis psicanalítica, convocando novos ajustes na condução da cura. Orientamos nossa discussão a partir da vida de Frida Kahlo, uma vez que a arte produzida por ela encontra-se fundada em acontecimentos de sua vida, acontecimentos de corpo e dor que, se articulam na constituição da sua feminilidade. Podemos assinalar dois encontros contingenciais, momentos cruciais que se inscrevem em sua economia psíquica, a saber: o acidente no ônibus e o amor por Rivera, que teriam, ambos, o estatuto de traumático. Identificada a um traço paterno, Kahlo ascende à feminilidade pelo viés da mascarada. Assim, sua obra configura-se como um tratamento frente ao limite da representação de seu sofrimento e de si mesma.
\end{abstract}

Palavras-Chave: feminilidade; corpo; Frida Kahlo; psicanálise; arte.

\section{Les amours de Frida Kahlo}

Cet article a l'intention d'approcher la place du féminin dans la clinique contemporaine et ses embarras dans la réussite de la vie amoureuse. Dans ce contexte, la question de l'amour et des nouveaux enveloppements symptomatiques demandent des réponses uniques, apportant des implications pour la praxis psychanalytique, appelant des nouveaux ajustements dans la conduite de la cure. Nous orientons notre discussion dès la vie de Frida Kahlo, une fois que l'art produite par elle est basée sur les événements de sa vie, des évènements de corps et la douleur, ceux qui sont articulés dans la constitution de leur féminité. Nous pouvons souligner deux rencontres cotingentes, des moments cruciaux qui s'inscrevent dans leur économie psychique, à savoir: l'accident d'autobus et l'amour pour Rivera, ceux qui auraient, tous les deux, le statut traumatique. Identifiée à une trace paternelle, Kahlo atteint la féminité par le biais de la mascarade. Ainsi, leur oeuvre se met en place en tant qu'un traitement face à la limite de la représentation de leur souffrance et de soi-même.

Mots-clés: féminité; corps; Frida Kahlo; psychanalyse; art.

\section{Loves of Frida Kahlo}

This article aims to analyze the role of women in the contemporary clinic and their love life entanglements. In this context, the question of love and the new symptomatic wraps demand singular answers, bringing implications for psychoanalytic praxis and calling for new adjustments in the conduction of cure. We chose to guide our discussion on the life of Frida Kahlo, since her art is based on her life events, events related to the body and pain, that are articulated in the constitution her femininity. We can point out two contingent meetings, two crucial moments that made a deep mark in her psychic economy, namely: the accident on the bus and the love for Rivera, both having the status of trauma. Identified to a paternal trait, Kahlo ascends to femininity through the figure of the masked woman. Thus, her work is characterized as a treatment facing the limits of representation of her suffering and herself.

Key-words: femininity; body; Frida Kahlo; psychoanalysis; art. 


\title{
Os amores de Frida Kahlo
}

\author{
Aléssia Silva Fontenelle
}

\section{Introdução}

Abordar o lugar do feminino na clínica atual implica, necessariamente, na delimitação de aspectos que predominam neste contexto contemporâneo. Com efeito, na pós-modernidade, frente ao declínio da Função Paterna e dos ideais, deparamo-nos com o que Lacan (1970/1992) define como a "subida ao zênite social do objeto $d$ ", ou seja, o domínio dos objetos sobre os sujeitos desbussolarizados, transformados em consumidores (reais e/ou virtuais), evidenciando o predomínio do gozo pulsional, gozo autístico, sobre os ideais da civilização.

Ante o fato de que tudo pode ascender ao lugar de objeto e que este mesmo objeto tornase triunfante sobre o simbólico (Brousse, 2004), a cultura acena com a possibilidade de satisfação do modo de gozo, através da proliferação de objetos como mais-de-gozar ${ }^{1}$, formalizando, com isso, novas formas de laço social.

Neste cenário, a questão do amor e dos novos envoltórios sintomáticos demandam respostas singulares, uma vez que, "não se crê mais na modernidade, nem na nova solução inventada, e tampouco nas velhas soluções" (Laurent, 2007, p. 21). Entretanto, se tais aspectos trazem implicações para a práxis psicanalítica, demandando novos ajustes na condução da cura, por outro lado a clínica nos tem demonstrado que os sujeitos continuam a se embaraçar na realização da vida amorosa.

Avançando nesta direção e advertidos por Lacan que, das mulheres, sabe-se uma a uma, optamos por pautar nossa discussão a partir de alguns aspectos relevantes da vida e obra da pintora Frida Kahlo, que se aproximou do feminino pelo viés da criação e ao longo de sua existência buscou insistentemente o amor, seduzindo homens e mulheres.

\section{Um pouco de sua história}

Em 06 de julho de 1907, nasce Magdalena Carmem Frieda² Kahlo Calderón, na cidade de Coyoacán, México, filha de Guilherme Kahlo e Matilde Calderón. Entretanto, ela afirmava ter nascido em 1910, ano em que se inicia a Revolução Mexicana.

Seu pai, alemão de origem, mudou-se para o México aos dezenove anos, logo após depararse com o comprometimento de sua carreira universitária, em decorrência de ataques epiléticos que passara a sofrer em consequência de um acidente. Com o falecimento de sua primeira esposa, casase com a mãe de Frida, que o estimula a seguir a mesma profissão do sogro, a de fotógrafo. Posteriormente, torna-se o primeiro fotógrafo oficial do Patrimônio Cultural Mexicano.

Logo após seu nascimento, sua mãe adoece e Frida passa a ser cuidada e amamentada por uma ama indígena. Com o desencadeamento da Revolução, então com três anos, sua família passa por dificuldades econômicas, dificuldades estas que, em alguma medida, comprometem a saúde de 
sua mãe, que começa a sofrer "desmaios" e "ataques" semelhantes aos do marido. Em entrevistas, a pintora evidencia sua ambivalência - amor e desprezo - com relação à mãe, que era chamada de minha chefe e descrita como "cruel (...) e muito amável, ativa, inteligente" (Herrera, 2011, p. 2829).

Aos 06 anos de idade, ela contrai poliomielite (paralisia infantil), que afeta permanentemente o funcionamento de sua perna direita. Permanece confinada no quarto por nove meses e, durante todo o período de sua convalescença, seu pai demonstra preocupação e cuidado com a filha. Após sua recuperação, a estimula a praticar esportes, vários deles considerados masculinos como o boxe, luta romana, futebol, além de tornar-se campeã de natação.

Em 1925, aos 18 anos, sofre um acidente de ônibus com seu namorado, no qual fratura a coluna vertebral, uma clavícula, várias costelas, além da pélvis esmagada. Um dos pés teve os ossos quebrados e sua perna atrofiada, em decorrência da poliomielite, sofreu onze fraturas. Ainda no acidente teve seu corpo literalmente traspassado, quando um corrimão rasgou as suas costas, saindo na vagina. Gravemente ferida, Frida passa a pintar durante sua longa convalescença (Fuentes, 1995).

A pintora foi descrita por seus biógrafos como uma mulher extremamente inteligente, culta, vibrante e com intenso senso de humor e irreverência. Sua imagem era marcada por roupas vistosas, preferencialmente trajes mexicanos nativos, com saias, anáguas, laços, tranças, fitas e jóias que escondiam seu corpo mutilado e seus espartilhos ortopédicos.

Por quase trinta anos, ela conviveu com a dor, cirurgias, hospitais, aparelhos ortopédicos e extensos períodos de recuperação na cama. Segundo Herrera (2011), apresentava "um amor peculiar pelo espetáculo como máscara para preservar a privacidade e a dignidade pessoal" (Herrera, 2011, p. 9).

Sua obra caracterizou-se pelo excesso, excesso de dor, de angústia, de cores, de solidão e por um insaciável desejo de viver. Sobre sua arte afirmou: "jamais pintei sonhos. Pintei minha própria realidade" (Frida, 1953/1995, p. 287). Nos quadros evidenciam-se "os seus próprios estados psíquicos, de uma forma ostentosa e às vezes irreverente, mas sua obra foi considerada excessivamente pessoal e autorreferente" (Lowe, 1995, p. 26).

\section{Dois momentos contingenciais}

Um traço que marca a arte de Frida é o fato desta encontrar-se fundada em acontecimentos de sua vida, acontecimentos de corpo e dor. Dentre estes, podemos assinalar dois encontros contingenciais, dois momentos cruciais que se inscrevem em sua economia psíquica, a saber, a poliomielite e o acidente no ônibus, que teriam, ambos, o estatuto de traumático.

Neste trabalho, proponho que possamos discutir de que forma esses eventos apontariam para a conformação de seu Sinthoma, ou melhor, sua solução existencial frente a algo traumático, a algo que estaria fora do simbólico. 
Sobre o traumatismo, Lacan (1964/1998) o traduz como encontro com o real (tiquê), algo que seria da ordem do impossível, ou seja, no trauma, o real encontra-se "apresentado na forma do que nele há de inassimilável"(Lacan, 1964/1998, p. 57).

Evidentemente, a sociedade contemporânea convive com um saber referente ao inconsciente, à feminilidade, à castração, entre outros, embora nenhum destes termos possa ir além de uma representação. Nesse sentido, a teoria freudiana já havia nos advertido que, tanto a morte quanto a feminilidade não teriam representação no inconsciente, permanecendo fora de qualquer alcance da palavra, ou seja, estaria "presente no mutismo que intercala entre os ditos" (André, 1998, p. 59).

Assim, cada sujeito lida com a feminilidade de forma única, e nessa direção Serge André ressalta que "o que uma mulher quer é que alguma coisa advenha ao lugar deste significante faltoso, que um ponto de apoio Ihe seja fornecido precisamente de lá onde o inconsciente a deixa abandonada. Essa reivindicação pode tomar diversos caminhos"' (André, 1998, p. 283).

Com efeito, com o advento da poliomielite, Frida se vê obrigada a permanecer isolada por nove meses em sua casa e quando retorna ao convívio da escola, passa a ser alvo de brincadeiras e zombarias, sendo chamada de "Frida perna de pau". Este período encontra-se marcado por uma mudança significativa em sua posição subjetiva. Ou seja, frente a esse encontro contingencial e na falta de uma inscrição simbólica, sua reação alternou entre a introversão, o isolamento e a supercompensação, ao transformar-se em uma garota levada e que buscava atividades que se caracterizavam como masculinas (Herrera, 2011).

Nesse sentido, aqui Frida evidencia uma das saídas possíveis frente à castração, a saída pelo complexo de masculinidade. Assim, frente à recusa de reconhecer a castração feminina, à nostalgia da falta-a-ter (Lacan, 1958/1998, p. 701), sua resposta seria a identificação imaginária com o pai.

Sobre a obrigatoriedade deste isolamento, a artista recorreu a uma invenção fantasmática que foi descrita por ela em seu diário:

Eu devia ter seis anos quando vivi intensamente a amizade imaginária com uma garota mais ou menos da mesma idade. Na janela do que então era meu quarto, [...] sobre um dos vidros mais baixos da janela eu soprava meu "bafo". E com um dedo desenhava uma "porta". Por essa "porta" eu saía na imaginação, com grande alegria e muita pressa, cruzava o amplo terreno que dali eu via até chegar a uma leiteria que se chamava PINZÓN... Eu entrava pelo O de PINZÓN e descia impetuosamente às entranhas da terra, onde "minha amiga imaginária" estava sempre à minha espera. Não me lembro de sua imagem nem da sua cor. Sei, porém, que era alegre - que ria muito. Silenciosamente. Era ágil. e dançava como se não tivesse peso nenhum. Observava seus movimentos e enquanto ela dançava eu the contava os meus problemas secretos. (Kahlo, 2011, p. 245-46) 
Essa passagem encontra-se materializada no autorretrato duplo, As duas Fridas (1939), no qual através da imagem redobrada, podemos observar a figuração da dimensão especular do eu. $\mathrm{Na}$ tela, ambas estão de mãos dadas e o coração de cada uma das Fridas encontra-se unido por uma mesma artéria. Na imagem à esquerda, percebemos uma artéria cortada por uma tesoura, que mancha de sangue o vestido branco. Já a figura à direita, tem em uma das mãos, um camafeu com o retrato de Diego Rivera.

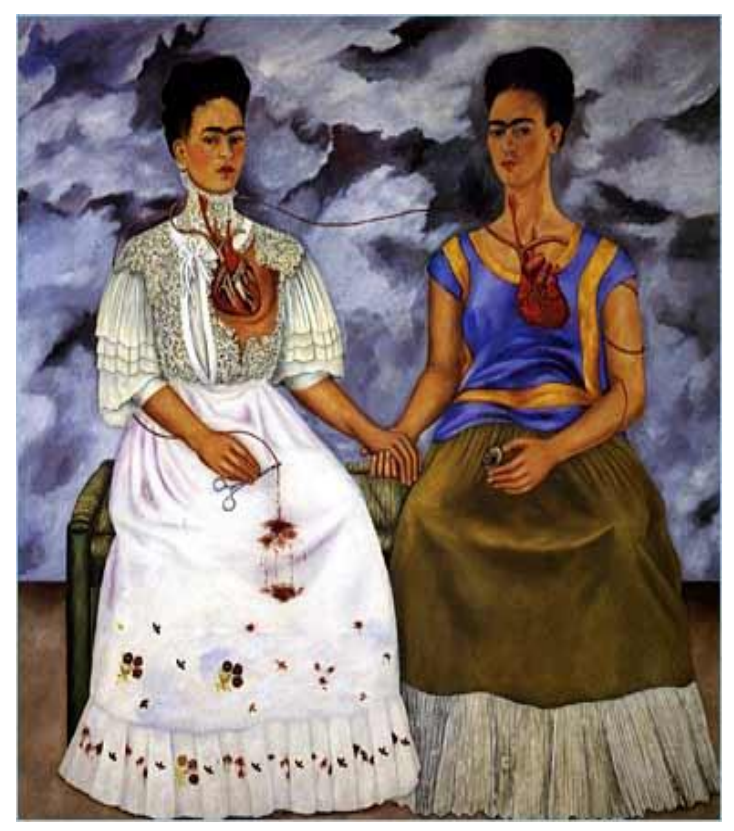

As Duas Fridas (1939)

Sobre a duplicação especular, Lacan (1932/1998) recorre ao termo imaginário para designar o registro psíquico que corresponderia ao eu do sujeito. Sua constituição estaria relacionada ao outro especular, no qual a imagem serviria de motivo comum, tanto ao ideal ou enamoramento, quanto ao ódio. O que irá mediar essa relação especular, será a introdução de um terceiro elemento, encarnado pelo pai, ou o lugar do Outro, nessa relação dual, ou seja, a introdução do simbólico.

Sendo a filha predileta devido à sua inteligência, e sem irmãos homens, Frida passa a ser estimulada intelectualmente pelo pai, durante a convalescência da poliomielite, tendo acesso a uma enorme variedade de leituras, o que despertaram seu interesse pela pintura e pela fotografia. Com isso, torna-se sua companheira nas suas incursões fotográficas, socorrendo-o quando sofria seus ataques (Coccoz, 2009).

Outro aspecto relevante foi o incentivo de seu pai para que ela estudasse medicina, algo incomum na cultura mexicana, o que a leva a entrar na Escola Nacional Preparatória. Neste ambiente, eminentemente masculino, Kahlo destaca-se pelo seu saber, pelo seu humor e por sua destreza nos jogos de palavras. 


\section{0 acidente}

No retorno da escola, um encontro contingencial e o sonho de ser médica se desfaz sob o impacto do bonde. Surpreende coincidência, Kahlo sofre o acidente na mesma idade em que seu pai sofreu. Embora o real não esteja representado como tal, ele passa a ser capturado pela repetição significante e se traduz em efeitos de angústia (André, 1998). Nesse sentido, esse momento de ruptura foi descrito por ela como um processo de mudança radical:

Algum tempo atrás, talvez uns dias, eu era uma moça caminhando por um mundo de cores, com formas claras e tangíveis. Tudo era misterioso e havia algo oculto; adivinhar-Ihe a natureza era um jogo para mim. Se você soubesse como é terrível obter o conhecimento de repente - como um relâmpago iluminando a terra! Agora vivo num planeta dolorido, transparente como gelo. É como se houvesse apreendido tudo de uma vez, numa questão de segundos. Minhas amigas e colegas tornaramse mulheres lentamente. Eu envelheci em instantes e agora tudo está embotado e plano. Sei que não há nada escondido; se houvesse, eu veria. (Kahlo, 2011, p. 27)

Podemos observar que o acontecimento traumático produz traços de afetação que, segundo Miller (2004), não podem ser liquidados pelo princípio do prazer. No traumatismo haveria, portanto, um desequilíbrio, um excesso de excitação permanente que se manteria no corpo, na psiquê, deixando traços nas situações ulteriores de vida do sujeito.

Esse acontecimento marca, traumatiza e deixa no corpo a presença da substância gozo. 0 acontecimento de corpo incide não sobre o corpo especular, mas sobre o corpo vivo, cuja consistência seria o gozo. Trata-se de um corpo que fala, de um corpo falado por certas contingências de um dizer, que produziram acontecimento, ou seja, um corpo que faz acontecimento com seu dizer (Alvarez, 2013). Segundo Lacan, as pulsões seriam, "no corpo, o eco de um dizer" (Lacan, 1975-1976/2007, p. 18).

Nessa perspectiva, o corpo seria "o que sobrevive ao naufrágio do simbólico" (Miller apud Laurent, 2008, p. 120), e o sujeito, afetado pela experiência que dele advém, recorre ao sintoma. Esse sintoma, enquanto modo de falar com o corpo, seria mais um solilóquio, um recurso que comportaria uma intensa conexão com a vida (Laia, 2013).

Assim, após o acidente e seus desdobramentos, a pintura torna-se uma parte de sua luta pela vida. Frida (1938) escreveu sobre sua iniciação na pintura:

Eu nunca pensei em pintura até 1926, quando fiquei de cama por causa de um acidente automobilístico. Eu estava morrendo de tédio na cama, com um colete de gesso [...] então decidi fazer alguma coisa. Roubei do meu pai algumas tintas a óleo, 
e a minha mãe encomendou pra mim um cavalete especial porque eu não conseguia ficar sentada, e comecei a pintar. (Frida apud Herrera, 2011, p. 85-86)

Momento de dor e esfacelamento corporal, ponto em que surge algo de insuportável que implicou um tratamento pelo ato. Freud (1914/1996) coloca que a arte seria da ordem da sublimação, o objeto de arte seria capaz de entrar no circuito simbólico, inserindo-se no discurso social, e "fazendo cessar o que de outra forma permaneceria no plano da não representação, do inacabado que faz o sujeito retornar" (Bastos, 2008, p. 92).

$\mathrm{Na}$ arte, a criação passa, necessariamente pela pulsão de morte, pelo vazio. Segundo Lacan, "toda arte se caracteriza por um certo modo de organização em torno desse vazio" (Lacan, 19591960/2008, p. 162). Frente a este, a pintura de Kahlo, por exemplo, no quadro A Coluna Partida (1947), torna-se a possibilidade de unificação desse corpo, tecendo a fixação da relação imaginária entre o corpo e sua imagem (Laurent, 2000). Nas palavras de Lacan:

Se vocês consideram o vaso, [...] como um objeto feito para representar a existência do vazio no centro do real que se chama a Coisa, esse vazio, tal como ele se apresenta na representação, apresenta-se, efetivamente, como nihil, como nada. E é por isso que o oleiro, [...] cria o vaso em torno desse vazio com sua mão, o cria assim como o criador mítico, ex nihilo, a partir do furo. (Lacan, 1959-1960, p. 153)

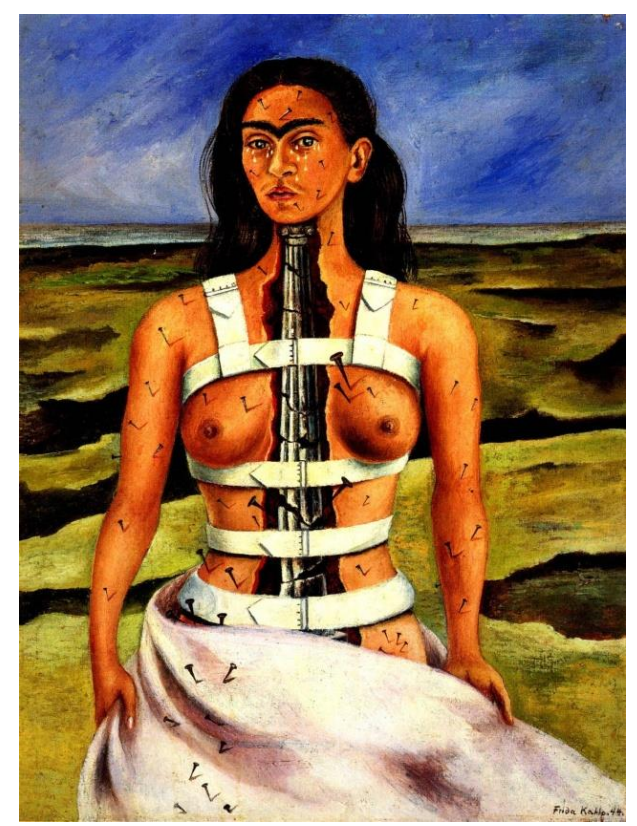

A Coluna Partida (1947)

Se por um lado em sua obra o furo, o vazio, o sem sentido transborda, por outro, a dimensão do belo surge em sua função de velar, possibilitando que se construam novas significações (Batista, 
1995). Assim, "é como se essa arte nos apresentasse a castração em contato direto, sem mediação" (Miller, 2008, p. 24).

A fala acima nos permite defender que, frente à irrupção do real, Kahlo recorre a um traço identificatório com pai, melhor dizendo, o amor pelo pai, em alguma medida, funcionaria como uma suplência frente a algo da ordem do impossível. $\mathrm{E}$, nesse sentido, ao encontrar-se apaixonada pelo pai, ela estaria, na definição de Freud, na posição histérica.

Uma das respostas ao conflito existente entre fazer-se mulher e certa aspiração à masculinidade seria o que Rivière (1929/2005) denominou de a mascarada. Frente à angústia da castração, o sujeito reveste, pela máscara da feminilidade, sua posição fálica, numa tentativa de evitar a represália masculina.

André (1998) ressalta que este mecanismo se dá em dois tempos, sendo o primeiro aquele em que necessita ser reconhecida como detentora do falo, falo aqui compreendido como significante da falta3. Assim, "ela não existe como mulher se não está assujeitada à função do falo" (André, 1998, p. 279). No segundo tempo, ela se separa do falo, posicionando-se como castrada, embora não-toda submetida a essa.

Entre estes dois momentos, ter e não ter o falo, surge a angústia da castração que seria resolvida pela devolução do falo. Ao separar-se dele, ao conceder esse dom ao homem, ela estaria dando aquilo que não tem e, consequentemente, obtendo o reconhecimento de sua feminilidade. Trata-se aqui, da ascensão ao feminino pelo viés do sacrifício (André, 1998).

Dessa forma, identificada a um traço paterno, fotógrafo profissional e pintor amador, Frida ascende à feminilidade pelo viés da mascarada, fazendo semblante fálico, dando a ver o que ela não é para ser amada. Assim, como afirma Lacan "é pelo que ela não é que ela pretende ser desejada, ao mesmo tempo que amada" (Lacan, 1958/1998, p. 701).

Sustentada pela estrutura, Frida avança na questão da feminilidade, abrindo mão do pai como objeto de amor e desejando ser colocada no lugar de objeto privilegiado de amor de outro homem.

\section{Um novo acidente - 0 amor}

Frida certa vez afirmou que "sofreu dois acidentes em sua vida. O primeiro ocorreu quando um bonde me atropelou... o outro acidente é Diego" (Herrera, 1984, p. 98 apud Bastos, 2008).

Nesta direção, Miller (2000) ressalta que o amor seria um encontro, encontro contingencial que possibilitaria que a Não Relação Sexual (NRS) "cesse de não se escrever". Tornando possível, através do amor, o encontro com o outro, com o parceiro.

Esse acidente tem início em 1922 quando Frida conhece Diego Rivera, um dos maiores pintores mexicanos de sua época, então contratado para pintar um mural na Escola Preparatória, onde ela estudava. Novo encontro aos 15 anos quando vai assisti-lo trabalhando e, junto com alguns colegas, Ihe faz uma série de molecagens. No ano seguinte, afirma às amigas que ainda terá um 
filho dele (Herrera, 2011, p. 39), desejo este que não foi realizado em decorrência a seguidos abortos.

Algum tempo após seu acidente, o procura para que possa avaliar suas pinturas, dedicandose a elas, após sua aprovação. Aos 22 anos casa-se com Rivera, então com 43 anos. Frida casou-se por duas vezes com o homem que escolheu e amou intensamente, como expressam suas cartas, poesias, pinturas e seu diário.

Entretanto, Frida certa vez expressou: "Tenho sido amada, amada, amada, não o suficiente. Por que nunca se quer o suficiente, uma vida só não basta" (Jamís, 1995, p. 254). Essa fala nos aponta para a questão do feminino, uma vez que esse sujeito por sua busca insistente por algo que pudesse reduzir a sua angústia e preencher o seu vazio, acreditando encontrar a felicidade pela via do amor (Bastos, 2008).

No amor, ao lugar do significante faltoso da feminilidade, convoca-se um sujeito o sujeito suposto pelo parceiro. Essa substituição é tanto mais facilitada quando existe uma identidade de estrutura entre a Mulher e o Sujeito lacaniano. Nem um nem outro existem como tal enquanto significantes: são apenas representados por um significante para outro significante. Quanto àquilo que são, isso não é jamais senão o lugar deixado vazio, inter-dito, entre dois significantes. (André, 1998, p. 283-284)

Entretanto, André (1998) ressalta que o amor não se reduz à relação estabelecida pela fala, encontrando em sua vertente real, seu limite. E com isso, a criação, principalmente a artística, seria uma tentativa de resposta à inexistência d'A Mulher, a criação seria a produção de um significante novo no lugar do significante faltoso. Esse significante novo não visa preencher esse furo, mas antes, revelá-lo e fazê-lo atuar enquanto vazio.

Essa questão se apresenta em 1934 quando Frida testemunha Rivera e sua irmã Cristina em pleno ato sexual, vindo a se separar deste. Em resposta a essa dor, a artista corta os cabelos que o marido tanto valorizava e pinta diversos quadros que expressam a dor da separação e o medo de perder o amor.

Em novembro de 1939 (quatro anos depois), oficializam uma segunda separação e dessa vez Frida, não só corta os cabelos, como retoma um comportamento presente em sua juventude, o de se vestir de forma masculina, negando assim, os atributos femininos (vestes tehuanas e os longos cabelos). 


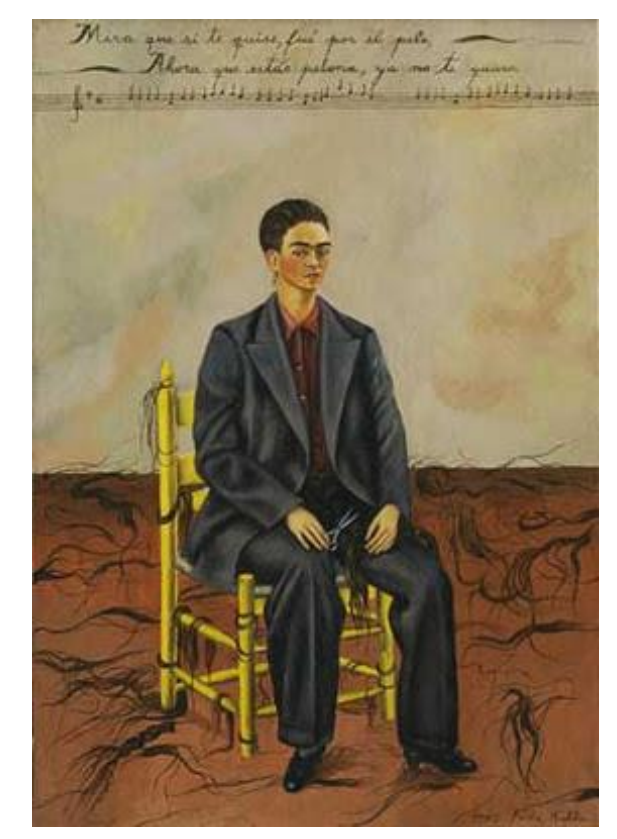

Auto-retrato com os Cabelos Cortados (1940)

Neste período, a artista produz o quadro Auto-retrato com Cabelo Cortado (1940), no qual está vestida como um terno masculino e tem escrito na parte de cima da tela um verso de uma canção mexicana: "olha, se te amei foi pelo teu cabelo, agora que estás careca, já não te quero". Essa dor que encontra o limite de qualquer representação, transforma-se em um objeto que teria a função de testemunho de uma significação singular, no qual os cabelos desorganizados pelo chão apontam na direção do mais além da significação.

Evidencia-se no objeto, ou melhor, na arte contemporânea, uma ruptura de sentido e ideal. Brousse (2008) argumenta que, por encontra-se do lado do Não-toda, outros limites se deslocariam e/ou apagariam, sendo estes:

1. A barreira entre imagem unificada do corpo, em sua dimensão imaginária e o organismo, em sua dimensão real;

2. A barreira do dentro-fora, tanto em relação ao espaço em que estariam situadas, quanto ao interior/exterior do corpo, íntimo/não íntimo, objetividade/objetividade; 3. A barreira entre o sentido próprio e o figurado, o que levaria a um efeito de interpretação metafórico numa perspectiva que o artista pretenda ética, além de um efeito "psicose";

4. A barreira entre símbolo e referente, o que levaria à produção de um "índex levantado", sem, contudo, trazer a explicação;

5. A barreira entre significante e semblante, ocorrendo sua permutação no simbólico; 
6. A barreira entre o objeto de arte e o objeto comum através da multiplicação "dos modos de fazer da arte como na natureza dos objetos, levando ao entrecruzamento entre objetividade e objetalidade. (Brousse, 2008, p. 175-176)

Nesse sentido, a arte de Frida produziria o efeito de fisgar o olhar como um ponto luminoso na paisagem. Lacan observa que o quadro oferece algo da ordem da satisfação da pulsão, na medida em que teria a função para o pintor de "dá a ver seu quadro (...). Ele oferece algo como pastagem para o olho, mas convida aquele a quem o quadro é apresentado a depor ali seu olhar, como se depõem as armas. Aí está o efeito pacificador, apolíneo, da pintura" (Lacan, 1964/1998, p. 99).

Em 1954 morre aos 47 anos, 11 dias após participar, ainda convalescendo de uma broncopneumonia, de uma passeata de protesto contra a intervenção norte-americana na Guatemala. Oficialmente sua morte seria decorrência de uma "embolia pulmonar", entretanto, havia suspeita de suicídio.

Herrera (2011) destaca que, embora um observador contemporâneo pudesse se surpreender com os amores, as batalhas, as separações e sofrimento que estiveram presentes ao longo do relacionamento de Frida e Diego, eles encontravam-se muito além de qualquer possibilidade de censura, o que nos leva a considerar que eles formaram, de fato, um casal contemporâneo.

Sobre o casal contemporâneo, Miller (1998) observa que podemos perceber uma modificação na relação entre os sexos no qual, tanto o homem, quanto a mulher, posicionar-se-iam como sujeitos de direito, mediando essa relação através do discurso jurídico.

Nesse contexto, do lado feminino haveria uma identificação ao modelo masculino pelo viés do semblante, da máscara. Entretanto, embora seu discurso demonstre certa desvalorização do amor e apresente uma tendência a verbalizar que o parceiro seria apenas um meio de gozo, esse discurso não passaria de um teatro, numa tentativa de velar sua preocupação com esta questão.

Miller (1998), avança nessa discussão quando destaca que a mulher moderna tenta existir como sujeito de direito e utiliza-se do discurso jurídico como se este pudesse orientar ao homem, como tratá-la. Essa seria uma forma de tentar fazer existir a relação sexual, no sentido de fazer existir a completude na relação com o outro. Contudo, quanto mais a mulher tenta existir pelo viés do sujeito de direito, menos o consegue, submersa sob a máscara da masculinidade.

Na relação de Frida com Rivera, seu amor por ele constrói-se como um sintoma, uma resposta singular frente ao sofrimento físico e as perdas, possibilitando certo tratamento à pulsão de morte, como podemos observar no relato em seu diário, seis meses após a amputação de sua perna:

11 de fevereiro de 1954 - Há seis meses amputaram-me a perna. Torturaram-me durante séculos e em alguns momentos quase enlouqueci. Continuo a sentir vontade de me suicidar. Diego é quem me impede, despertando em mim a vaidade de pensar 
que posso fazer falta. Ele disse, e eu creio nele. Mas nunca sofri tanto na vida. Esperarei algum tempo. (Kahlo, 2011, p. 144)

Evidentemente, podemos perceber a presença de Thanatos sob Eros, no percurso da organização da libido a pulsão de morte. Considerando que o amor presentifica o pulsional, Lacan (1972-1973/1985), o aborda pela ambivalência, como a "hainamoration, uma enamoração feita de ódio (haine) e de amor, um amórdio" (Lacan, 1972-1973/1985, p. 122), ou seja, esse novo significante, amórdio, liga amor e ódio. Esse aspecto se inscreve frente ao fato de que o homem, ao protelar o momento de morrer, busca o primeiro objeto de satisfação, ou seja, busca o objeto perdido, e em seu lugar depara-se com o objeto metonímico que desliza na cadeia significante. Portanto, ao não se ter o objeto de desejo, demanda-se mais, mais ainda, demonstrando que o amor inscreve-se tendo como referência, o gozo perdido.

Se o amor "vem em suplência à relação sexual" (Lacan, 1972-1973/1985, p. 62), Frida ao se deparar com um real que não se decifra, recorre à linguagem, através das cartas e da arte, tentando inscrever seus afetos, angústias e o amor por Rivera, sem que os significantes alcancem sua dimensão.

Oito dias antes de sua morte, Frida assina seu último quadro Viva La Vida (1954), e nele escreve seu nome, o de sua cidade natal e seu país. Quadro pintado com cores intensas, evidenciando sua paixão pela via da pintura (Herrera, 2011, p. 362). Na manhã de 13 de julho de 1954, Frida foi encontrada morta, então com 47 anos.

Para finalizar, podemos propor que, o amor pela pintura e por Rivera, tomam o estatuto de causa, configurando-se enquanto sintoma singular, "sintoma com significação pessoal" (Laurent, 2011, p. 52). Portanto, ante o limite de representação de seu sofrimento, ou mesmo à impossibilidade de representar-se a si mesma em cada autorretrato, a obra de Frida configura-se como um tratamento ao limite desse saber ${ }^{4}$.

\section{Notas:}

${ }^{1}$ Mais-de-gozar - gozo fálico enquanto substituição significante.

${ }^{2}$ Com a ascensão do nazismo, modifica a grafia de seu nome para Frida.

3 Falo - "é aquilo no qual se inscreve a falta, está no lugar da falta" (Bleichmar, 1984, p. 22).

${ }^{4}$ Esse artigo é resultado do projeto de pesquisa apresentado para fins de ingresso no doutorado do Programa de Pós-Graduação em Teoria Psicanalítica pela Universidade Federal do Rio de Janeiro (UFRJ).

\section{Referências Bibliográficas}

Alvarez, A. (2013). Falar com qual corpo? Recuperado de http://www.enapol.com/pt/template.php?file=Textos/Hablar-con-cualcuerpo PatricioAlvare z.html.

André, S. (1998). O que quer uma mulher? Rio de Janeiro: Jorge Zahar. 
Bastos, M. (2008). Sublimação, o trauma e o corpo: Frida Kahlo. (Dissertação de mestrado). Universidade Veiga de Almeida, Campus Tijuca. Recuperado de http://www.uva.br/mestrado/dissertacoes_psicanalise/2_MARLI_BASTOS_DISSERTACAO_A_S UBLIMACAO_O_TRAUMA_E_O_CORPO_FRIDA_KAHLO_Inteira.pdf.

Bleichmar, H. (1984). O Édipo em Lacan - I. In Bleichmar, H. (Org.). Introdução ao estudo das perversões: teoria do Édipo em Freud e Lacan (pp. 17-25). Porto Alegre: Artes Médicas.

Brousse, M.-H. (2004). Uma dificuldade na análise das mulheres: a devastação da relação com a mãe. In MILLER, J.-A. (Org.). Ornicar? 1 - de Jacques Lacan a Lewis Carroll (pp. 57-67). Rio de Janeiro: Zahar.

Brousse, M.-H. (2005). Feminismo. Scilicet dos nomes do pai (pp. 55-56). Rio de Janeiro: EBP.

Brousse, M.-H. (2008). O objeto de arte na época do fim do belo: do objeto ao abjeto. Opção Lacaniana - Revista Brasileira Internacional de Psicanálise (52), 173-177. São Paulo: Eólia.

Coccoz, V. (2009). Las mujeres el amor, el cuerpo. In ELDAR, S. (Org.). Mujeres, una por una (pp. 169-194). Madri: Gredos.

Freud, S. (1996). O Moisés de Michelangelo. In J. Salomão (Trad.) Edição standard brasileira das obras psicológicas completas de Sigmund Freud (Vol. 13, pp. 249-280). Rio de Janeiro: Imago (Trabalho original publicado em 1914).

Frida, K. (1995). Tradução do diário com comentários. O diário de Frida Kahlo: um auto-retrato íntimo (p. 201-287). Rio de Janeiro: José Olympio.

Fuentes, C. (1995). Introdução. O diário de Frida Kahlo: um auto-retrato íntimo (pp. 07-24). Rio de Janeiro: José Olympio.

Herrera, H. (2011). Frida: a biografia. São Paulo: Globo.

Jamís, R. (2003). Frida Kahlo. Barcelona: Circe.

Kahlo, F. (2011). Cartas apaixonadas de Frida Kahlo. Rio de Janeiro: José Olympio.

Lacan, J. (2008). O Seminário, livro 07: a ética da psicanálise . Rio de Janeiro: Jorge Zahar (Trabalho original publicado em 1959-1960).

Lacan, J. (1998). O Seminário, livro 11: os quatro conceitos fundamentais da psicanálise. Rio de Janeiro: Zahar (Trabalho original publicado em 1964).

Lacan, J. (1992). O Seminário, livro 17: o avesso da psicanálise. Rio de Janeiro: Zahar (Trabalho original publicado em 1969-1970).

Lacan, J. (1985). O Seminário, livro 20: mais, ainda. Rio de Janeiro: Zahar (Trabalho original publicado em 1972-1973).

Lacan, J. (1998). O estádio do espelho como formador da função do eu tal como nos é revelada na experiência psicanalítica. In Escritos (pp. 96-103). Rio de Janeiro: Zahar (Trabalho original publicado em 1949).

Lacan, J. (1998). A significação do falo. Escritos (pp. 692-703). Rio de Janeiro: Zahar (Trabalho original publicado em 1958). 
Lacan, J. (2007). O Seminário, livro 23: o sinthoma. Rio de Janeiro: Zahar (Trabalho original publicado em 1975-1976).

Laia, S. (2013). Falar com o corpo, um solilóquio e a experiência analítica. Recuperado de http://www.enapol.com/pt/template.php?file=Textos/Hablar-con-el-cuerpo-un-soliloqui o-y-la experiencia-analitica_Sergio-Laia.html.

Laurent, É. (2000). As paixões do ser. Salvador: Kalimeros.

Laurent, É. (2007). A disparidade no amor. Curinga - Revista da Escola Brasileira de Psicanálise, (24), 21. Belo Horizonte: EBP.

Laurent, É. (2008). A classificação. Opção Lacaniana - Revista Brasileira Internacional de Psicanálise, (51), 120. São Paulo: Eólia.

Laurent, É. (2011). Políticas do sintoma na arte, na ciência e na clínica psicanalítica. Opção Lacaniana - Revista Brasileira Internacional de Psicanálise, (61), 41-52. São Paulo: Eólia.

Lowe, S. M. (1995). Ensaio. O diário de Frida Kahlo: um auto-retrato íntimo (pp. 25-29). Rio de Janeiro: José Olympio.

Miller, J.-A. (1998). O osso de uma análise. Salvador: EBP.

Miller, J.-A. (2000). A teoria do parceiro. Os circuitos do desejo na vida e na análise (pp. 153-207).

Rio de Janeiro: Contra Capa.

Miller, J.-A. (2004). Biologia lacaniana e acontecimentos de corpo. Opção Lacaniana - Revista Brasileira Internacional de Psicanálise, (41), 07-67. São Paulo: Eólia.

Miller, J.-A. (2008). A imagem do corpo em psicanálise. Opção Lacaniana - Revista Brasileira Internacional de Psicanálise, (52), 17-27. São Paulo: Eólia.

Riviere, J. (2005). A feminilidade como máscara. Psyche, $9(16), 13-24$. São Paulo.

Citacão/Citation: Fontenelle, A. S. (nov. 2015 a abr. 2016). Os amores de Frida Kahlo. Revista aSEPHallus de Orientação Lacaniana, 11(21), 88-101. Disponível em www.isepol.com/asephallus. doi: 10.17852/1809709x.2019v11n21p88-101.

Editor do artigo: Tania Coelho dos Santos.

Recebido/Received: 02/04/2016 / 04/02/2016.

Aceito/Accepted: 18/04/2016 / 04/18/2016.

Copyright: (C) 2013 Associação Núcleo Sephora de Pesquisa sobre o moderno e o contemporâneo. Este é um artigo de livre acesso, que permite uso irrestrito, distribuição e reprodução em qualquer meio, desde que o autor e a fonte sejam citados/This is an open-access article, which permites unrestricted use, distribution, and reproduction in any medium, provided the author and source are credited. 